\title{
Population Structure, Pathogenicity, and Mating Type Distribution of Magnaporthe oryzae Isolates from East Africa
}

\author{
Geoffrey Onaga, Kerstin Wydra, Birger Koopmann, Yakouba Séré, and Andreas von Tiedemann
}

First, third, and fifth authors: Division of Plant Pathology and Crop Protection, Department of Crop Sciences, and second author: CLB-Tropical and Subtropical Agriculture and Forestry, Georg-August-University Göttingen, Germany; and fourth author: Africa Rice Center, P.O. Box 33581, Dar es Salaam, Tanzania.

Accepted for publication 23 March 2015.

\begin{abstract}
Onaga, G., Wydra, K., Koopmann, B., Séré, Y., and von Tiedemann, A. 2015. Population structure, pathogenicity, and mating type distribution of Magnaporthe oryzae isolates from East Africa. Phytopathology 105:1137-1145.

Rice blast, caused by Magnaporthe oryzae, is one of the emergent threats to rice production in East Africa (EA), where little is known about the population genetics and pathogenicity of this pathogen. We investigated the genetic diversity and mating type (MAT) distribution of 88 isolates of $M$. oryzae from EA and representative isolates from West Africa (WA) and the Philippines (Asia) using amplified fragment length polymorphism markers and mating-type-specific primer sets. In addition, the aggressiveness of each isolate was evaluated by inoculating on the susceptible Oryza sativa indica 'Co39', scoring the disease severity and calculating the disease progress. Hierarchical analysis of molecular variance revealed a low level of genetic differentiation at two levels $\left(\mathrm{F}_{\mathrm{ST}}\right.$ 0.12 and $\mathrm{F}_{\mathrm{CT}} 0.11$ ). No evidence of population structure was found among the 65 isolates from EA, and gene flow among EA populations was high.

derived from within populations. However, the populations from Asia and WA were moderately differentiated from EA ones. The spatial analysis of principal coordinates and STRUCTURE revealed overlapping between individual M. oryzae isolates from EA, with limited distinctness according to the geographic origin. All the populations were clonal, given the positive and significant index of association $\left(I_{A}\right)$ and standardized index of association $\left(r_{d}\right)$, which indicates a significant $(P<0.001)$ departure from panmixia $\left(I_{A}\right.$ and $\left.r_{d}=0\right)$. Both MAT1-1 and MAT1-2 were detected. However, MAT1-1 was more prevalent than MAT1-2. Pathogenicity analysis revealed variability in aggressiveness, suggesting a potential existence of different races. Our data suggest that either M. oryzae populations from EA could be distributed as a single genetic population or gene flow is exerting a significant influence, effectively swamping the action of selection. This is the first study of genetic differentiation of rice-infecting $M$. oryzae strains from EA, and may guide further studies on the pathogen as well as resistance breeding efforts.
\end{abstract} Moreover, pairwise population differentiation $\left(G_{S T}\right)$ in EA populations ranged from 0.03 to 0.04 , suggesting that $>96 \%$ of genetic variation is
Additional keywords: AFLP.
Rice is a staple food for more than 3 billion people worldwide, and a significant income source to rural communities in developing countries. In East Africa (EA), rice has gained importance only recently. The production area in the three EA countries-Uganda, Rwanda, and Tanzania - increased from approximately 452,000 ha in 1999 to $1,223,910$ ha in 2011 (FAOSTAT 2011). This area expansion and the ongoing intensification of rice production could potentially contribute to increased rice supply in the region that was formerly dependent on maize and sorghum as major cereals. However, rice production in EA faces a double burden of destructive diseases and the knowledge gap to cope with disease outbreaks. Among the various diseases, rice blast caused by Magnaporthe oryzae is an eminent threat to rice production. In fact, an unexpected blast outbreak was observed in farmers' fields in Kenya in 2009, leading to $48 \%$ yield losses (Kihoro et al. 2013). Moreover, field observations in Tanzania, Burundi, and Rwanda indicate the spread of the disease from traditional to new rice-growing areas, a situation that is only anticipated to worsen with increasing temperatures due to climate change (Liu et al. 2010; Mwalyego et al. 2011). How far this spread of the disease in EA indicates the evolution of novel pathotypes and enhancement of population diversity is not known.

Previous studies of genetic variation in $M$. oryzae populations found higher levels of genetic variation in field populations collected from South, East, and Southeast Asia than in other

Corresponding author: G. Onaga; E-mail address: gonaga@gwdg.de regions (Saleh et al. 2014; Zeigler 1998). However, fewer lineages were detected in the United States (Correll et al. 2009; Levy et al. 1991; Xia et al. 1993, 2000), Europe (Piotti et al. 2005; Roumen et al. 1997), Iran (Javan-Nikkah et al. 2004), Argentina (Consolo et al. 2008), Colombia (Levy et al. 1993; Zeigler 1998), Cuba (Fuentes et al. 2003), and West Africa (Takan et al. 2012), which is probably consistent with the hypothesis that asexual reproduction is dominant in the life cycle of $M$. oryzae. Commonly reported causes of genetic variability in Asian M. oryzae populations include high levels of genetic instability of traits such as pathogenicity, morphology, and fertility (Maciel et al. 2014), which could be congruent with the large number of pathotypes in some of the field populations reported.

However, there have been no studies on the genetic structure of the rice infecting $M$. oryzae field populations in EA. Improving our understanding of the genetic diversity, mating type (MAT) distribution, and aggressiveness of this pathogen is the most promising strategy that will provide a basis for implementation of various management approaches, including host plant resistance.

Various methods have been used to study the genetic diversity and population structure in M. oryzae, such as MGR 586 repetitive DNA sequence (Borromeo et al. 1993), Pot2 (Kachroo et al. 1994), randomly amplified polymorphic DNA (RAPD) (Sere et al. 2007), amplified fragment length polymorphism (AFLP) (Thuan et al. 2006), simple sequence repeats (SSR) (Brondani et al. 2000; Saleh et al. 2014), and pathogenicity tests on differential sets of rice genotypes (Levy et al. 1991). From these methods, AFLP and SSR provide more sensitive and reliable analysis for individual genotype profiling. The AFLP technique is particular suitable for genetic diversity analysis due to simultaneous analysis of a large number of 
polymorphic loci and high reproducibility due to high stringency of polymerase chain reaction (PCR), compared with RAPD (Liu and Cordes 2004). Due to these advantages, AFLP markers have been advocated as a powerful genetic marker system for assessing population structure and individual identity (Gerber et al. 2000).

Our objective here was to assess the extent of genetic variation in EA field populations of $M$. oryzae with AFLP markers, and determine MAT distribution and virulence. The present study provides the first estimates of genetic structure of field populations of M. oryzae from EA.

\section{MATERIALS AND METHODS}

Sampling, monoconidial isolation, and cultivation of fungal isolates. Isolates were collected in 2009 and 2011 from three EA countries: Rwanda, Uganda, and Tanzania (Fig. 1). For comparative purposes, isolates from West Africa and the Philippines (Asia) were included. Eight sampling points (farmers' fields) per site were considered. One to nine cultivars were sampled per location, with one to five lesion-bearing leaves collected per cultivar and one isolate collected per leaf. The number of sampling points and sites sometimes varied, according to the rice field and disease availability. Prior to isolation, each leaf sample was placed on glass rods in petri dishes with wet filter papers and incubated in continuous fluorescent light for 1 to 2 days at $25^{\circ} \mathrm{C}$ until conidiophores bearing conidia emerged from stromatal tissue beneath leaf stomata. The sporulating lesions were examined under a stereomicroscope and a group of conidia was aseptically transferred with a transfer needle to V8 agar. The pathogen was identified based on its morphological growth pattern and spore shape. To obtain single conidial isolates, conidia were streaked onto water agar. Individual, germinating conidia were identified with

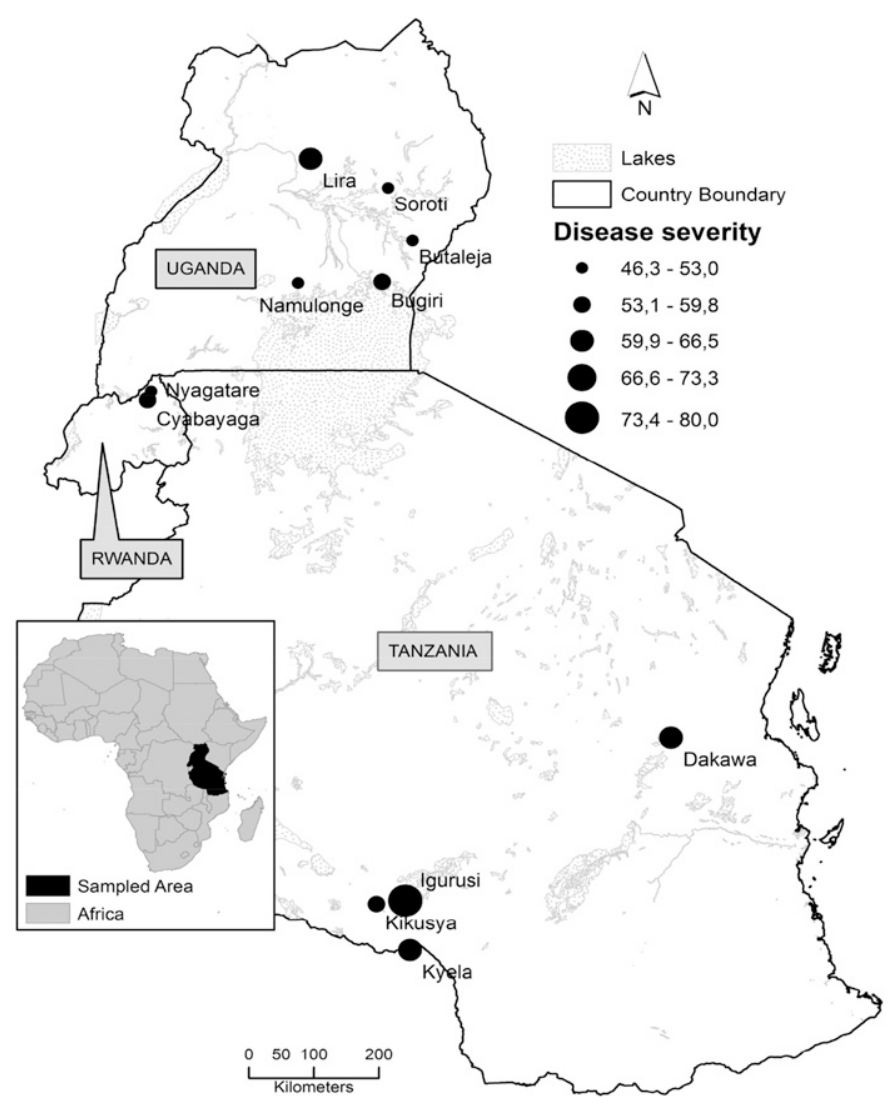

Fig. 1. Geographic sites of rice fields in East Africa where Magnaporthe oryzae strains were sampled. Mean percent disease severity scores (black dots) for the different sampling sites and respective locations are indicated. The size of the dots indicates the level of disease severity. a stereomicroscope and aseptically transferred and cultured in V8 agar. For long-term storage, each culture was overlaid with several sterilized filter paper sections and incubated at $25^{\circ} \mathrm{C}$. After 10 to 12 days of incubation, the colonized filter paper sections were lifted from the agar surface, placed in sterile, empty petri dishes, allowed to dry for 3 days at room temperature, and stored at $-20^{\circ} \mathrm{C}$.

DNA extraction. In total, 88 isolates of $M$. grisea (Table 1) from the collection stored in the Division of Plant Pathology and Crop Protection, Georg-August University, Goettingen, Germany, were used for AFLP analysis. To obtain mycelia, plugs harvested from 8-day-old cultures were inoculated into a 1,000-ml flask containing $250 \mathrm{ml}$ of liquid Fries medium at room temperature for 7 to 8 days with constant shaking on a rotary shaker. Mycelial mats were harvested, freeze dried, and ground in liquid nitrogen to a fine powder. Approximately $40 \mathrm{mg}$ of the powdered mycelia was used for DNA isolation using a modification of the cetyltrimethylammonium bromide (CTAB) method (Brandfass and Karlovsky 2008), by combining the sodium acetate-sodium dodecyl sulfate with CTAB extraction.

AFLP analysis. AFLP analysis was conducted according to a method modified from Vos et al. (1995). The primary template for preamplification reaction consisted of $125 \mathrm{ng}$ of genomic DNA. Genomic DNA was first digested with $10 \mathrm{U}$ of EcoRI at $37^{\circ} \mathrm{C}$ overnight followed by a second digestion with $5 \mathrm{U}$ of $\mathrm{Tr} \mathrm{I}$ (Fermentas GmbH, St. Leon-Rot, Germany) at $65^{\circ} \mathrm{C}$ for $2 \mathrm{~h}$. The digested samples were ligated overnight with $1.0 \mathrm{U}$ of T4 DNA ligase (Fermentas $\mathrm{GmbH}$ ) and $10 \mu \mathrm{M}$ EcoRI and TruI adapters in a final volume of $20 \mu \mathrm{l}$ at room temperature. The ligation products were diluted 10 -fold with ultrapure water and $1 \mu \mathrm{l}$ of the resulting dilution was used for preselective amplification with EcoRI-A and TruI-C primers $(10 \mu \mathrm{M}), 10 \mathrm{mM}$ each dNTP, $50 \mathrm{mM} \mathrm{MgCl}_{2}, 5 \mathrm{U}$ of Taq DNA polymerase, and $10 \times$ Taq polymerase buffer $(50 \mathrm{mM}$ Tris$\mathrm{HCl}$ [pH 7.5], $50 \mathrm{mM}$ magnesium acetate, and $250 \mathrm{mM}$ potassium acetate) in a total volume of $25 \mu \mathrm{l}$. Two replicate AFLP reactions per individual were used to eliminate variation due to anomalous PCR products or artifacts of detection in individual analysis. PCR was performed for 25 cycles, which consisted of $30 \mathrm{~s}$ at $94^{\circ} \mathrm{C}, 1 \mathrm{~min}$ at $56^{\circ} \mathrm{C}$, and $1 \mathrm{~min}$ at $72^{\circ} \mathrm{C}$ in an Eppendorf Master Cycler (NethelerHinz GmbH, Hamburg, Germany). The products of the preselective amplification step were diluted 1:10 with ultrapure water and subjected to selective amplification. The amplification reaction mix was similar to the preselective amplification, except that labeled EcoRI-ACA-Dy635-5 carboxyfluorescein, EcoRI-ACC-Dy750 blue fluorescein, EcoRI-AGA-Dy680 green fluorescein (Dyomics, Jena, Germany), and TruI-CCC primers were used. The thermocycler program consisted of two phases. The first phase was performed with a touchdown cycling profile of 12 cycles with a step-down of annealing temperature by $0.7^{\circ} \mathrm{C} /$ cycle: $30 \mathrm{~s}$ at $94^{\circ} \mathrm{C}$, $30 \mathrm{~s}$ at 65 to $57.3^{\circ} \mathrm{C}$, and $1 \mathrm{~min}$ at $72^{\circ} \mathrm{C}$. The second phase consisted of 23 cycles of $30 \mathrm{~s}$ at $94^{\circ} \mathrm{C}, 1 \mathrm{~min}$ at $56^{\circ} \mathrm{C}$, and $1 \mathrm{~min}$ at $72^{\circ} \mathrm{C}$.

Preparation of DNA amplification fragments for separation by capillary electrophoresis. The selectively amplified DNA fragments were diluted 1:10 with ultrapure water, and $2.5 \mu \mathrm{l}$ of each sample was loaded into respective microtiter plate wells. A 30- $\mu$ l separation solution (formamide incorporated) mixed with a size standard 600 (Beckman Coulter, Fullerton, CA) was added and each well was overlaid with a drop of Sigma mineral oil (M5904). The microtiter plates containing the reaction mixtures were briefly spun and the samples were run in denaturing polyacrylamide gel using an automated DNA sequencer (CEQ 8000 genetic analysis system; Beckman Coulter). The AFLP patterns were captured and peaks were assigned to base pair sizes using the default analysis parameter and analyze the data window in the CEQ System Software. To detect peaks of interest, the slope threshold and the relative peak height threshold were set at 50 and 10, respectively. All peak heights were compared with a reference peak of the same color based on the migration time for each of the dyes used. Further data processing, including background subtraction and signal matching, was 
performed according to Weiberg and Karlovsky (2009). The peak data were converted into a binary matrix using the AFLP feature of the CEQ System. The AFLP feature creates bins from fragments with sizes that fall within a user-defined bin width. For each of the possible fragments, a " 1 " is assigned if a fragment is found in that sample and " 0 " if the fragment is absent. A table of $1 \mathrm{~s}$ and $0 \mathrm{~s}$ is created and exported to an excel spreadsheet. Only PCR fragments that show high reproducibility in the two repeat runs were used for further analyses.

Population genetic structure analysis. The genetic diversity within and between populations was assessed with POPGENE, version 1.3.2 (Yeh and Boyle 1999). Shannon's index (I) and Nei's diversity index $(H)$ were also calculated using the default settings in POPGENE. The genetic differentiation $\left(G_{S T}\right)$ among populations was calculated as $G_{S T}=D_{S T} / H t$. Gene flow $(\mathrm{Nm})$ between any two studied populations was estimated as $N m=0.5\left(1-G_{S T}\right) / G_{S T}$. The average allele frequency of alleles unique to one population, across loci $(p[1])$, or private alleles was estimated using GENALEX. We used the poppr $\mathrm{R}$ package to generate a Maynard Smith index of association $\left(I_{A}\right)$, which assesses multilocus linkage disequilibrium, and another estimator, $r_{d}$, to correct for the bias in $I_{A}$ that may arise due to the influence of increasing number of loci. We estimated multilocus genotypic diversity using Stoddart and Taylor's index $G$ (Stoddart and Taylor 1988), and multilocus genotypic evenness (the distribution of genotypes in a sample) using the index $E_{5}$ (Grünwald et al. 2003). Two methods were used to determine population genetic structure. First, the program Tools for Population Genetic Analysis (TFPGA) (Miller 1997) was used to calculate $\theta$, an unbiased estimator of Wright's $\mathrm{F}_{\mathrm{st}}$. We calculated $95 \%$ confidence intervals around the estimates of $\theta$ by bootstrapping with 1,000 replicates. Second, the population genetic analysis program ARLEQUIN 3.5 (Excoffier et al. 2005) was used to assess the interpopulation genetic structure without assuming Hardy-Weinberg equilibrium by performing an analysis of molecular variance (AMOVA).

Cluster analysis of AFLP data. Cluster analysis of the presence (1) or absence (0) data matrix was performed with two methods. We used principle coordinate analysis (PCoA) based on Nei's distances between all pairs of AFLP genotypes using GENALEX 6.2 (Peakall and Smouse 2006; Nei 1978), which generated a two-dimensional principal component analysis plot showing the distribution of $M$. oryzae strains among the studied populations. Second, we used the model-based program STRUCTURE 2.3 (Pritchard et al. 2000), which implements a clustering algorithm based on a Bayesian model to assign individuals to a number of clusters (K) or populations. To estimate the number of Ks, 10 independent runs were performed for each number of possible clusters $(K=1$ to 10$)$, without any prior information on the origin of individual isolates. For each run, we used a burn-in period of $1 \times 10^{5}$ iterations followed by a run length of $1 \times 10^{5}$ iterations, using a model with correlated allele frequencies and admixture among populations. The number of populations that best represent the observed data under the model implemented was determined using STRUCTURE output, based on the rate of change in log probability of data ( $\mathrm{LnP}[\mathrm{D}])$ between successive Ks. The most probable value of $\mathrm{K}$ was determined by $\Delta \mathrm{K}$, an ad hoc quantity related to the second-order change in the Ln P(D) with respect to the number of clusters inferred by STRUCTURE (Evanno et al. 2005). The estimated membership coefficients for each individual in each cluster in a Q matrix were passed as input to the software package DESTRUCT for visualization.

Pathogenicity assays and statistical analysis. Plant inoculations were performed on short-duration dwarf Oryza sativa indica 'Co39', with high susceptibility to tropical blast isolates. The plants were grown in the greenhouse at $25 \pm 5^{\circ} \mathrm{C}$ with a photoperiod of $14 \mathrm{~h}$ for 23 days. $M$. oryzae isolates were grown in petri dishes containing V8 agar under $14 \mathrm{~h}$ of fluorescent light at $25^{\circ} \mathrm{C}$ for 12 days. Three days prior to inoculation, cultures were exposed to low levels of visible and near-UV radiation to maximize sporulation.
Conidia were harvested with sterile distilled water and the concentration was adjusted to $1 \times 10^{5}$ conidia/ml after filtration through two layers of Miracloth. Pathogenicity tests were performed by spraying a conidial suspension containing $0.05 \%$ Tween 20 onto rice seedlings at four- to five-leaf stages. Inoculated plants were kept in a humidified growth chamber in the dark at $25^{\circ} \mathrm{C}$ for $24 \mathrm{~h}$, before returning to the greenhouse at $25 \pm 5^{\circ} \mathrm{C}$. Leaf blast was assessed 4 to 12 days after inoculation using a disease evaluation scale from 0 to 9 (Silva et al. 2009). Inoculations were repeated two times using three replicates per repeat to confirm lesion categorization into resistant or susceptible types. Disease severity ratings between the two repeats remained consistent. Violation of assumptions of normality was tested on both datasets using the Shapiro-Wilks test, and the data set with minimal bias in the distribution of residuals was used for calculating the area under the disease progress curve (AUDPC) using the midpoint rule method (Campbell and Madden 1990) in order to compare the different isolates. Analysis of variance for the final rice blast severity (\%) and AUDPC was performed using SAS 9.3, and the least significant difference test at 0.05 probability level was used for mean comparisons.

MAT distribution. Two isolates, IN1 (MAT1-1) and OG5 (MAT1-2), kindly provided by Dr. Didier Tharreau (CIRAD, Montpellier, France), were used as testers in this study. DNA of the testers was isolated as described above. Isolates used for MAT determination are indicated in Table 1. Two singleplex PCR amplifications were performed with MAT-specific primers previously used by Consolo et al. (2005): A1 (5'-AGCCTCATCAACGGCAA-3') andA5 (5'-GGCACGAACATGCGATG- $\left.3^{\prime}\right)$ for MAT1-1 and B15 $\left(5^{\prime}\right.$-CTCAATCTCCGTAGTAG-3') and B16 (5'-ACAGCAGTA TAGCCTAC- $3^{\prime}$ ) for MAT1-2. The PCR had a final volume of $20 \mu \mathrm{l}$ containing $80 \mathrm{ng}$ of template DNA, 10× Taq polymerase buffer (Bioline, Luckenwalde, Germany), $2.5 \mathrm{mM}$ each dNTP, $50 \mathrm{mM}$ $\mathrm{MgCl}_{2}$, TaqDNA polymerase at $5 \mathrm{U} / \mu \mathrm{l}$, and $0.01 \mathrm{mM}$ each primer. Thermal cycling conditions included an initial denaturation step at $95^{\circ} \mathrm{C}$ for 5 min followed by 30 cycles of $95^{\circ} \mathrm{C}$ for $45 \mathrm{~s}, 58$ and $62.5^{\circ} \mathrm{C}$ for MAT1-2 and MAT1-1, respectively, for $1 \mathrm{~min}$, and $72^{\circ} \mathrm{C}$ for $1 \mathrm{~min}$; and a final elongation step at $72^{\circ} \mathrm{C}$ for $5 \mathrm{~min}$. PCR products were separated in a $1.2 \%$ agarose gel at $66 \mathrm{~V}$ for $3 \mathrm{~h}$, stained with ethidium bromide, and photographed.

\section{RESULTS}

Genetic diversity and population structure. The three selected AFLP primer combinations generated a total of 289 loci, of which 198 were phylogenetically informative; that is, present or absent in at least two strains, with alleles ranging in size from 60 to $700 \mathrm{bp}$ across all 88 isolates of the five populations. The percentage of polymorphic loci at the population level ranged from $31.3 \%$ (West Africa) to $68.7 \%$ (Uganda) (Table 2). To distinguish clonal and recombinant structures in all populations, multilocus genotypes (MLG) and $I_{A}$ were used. We detected clonality in all the populations, given the positive $I_{A}$ and $r_{d}$ values (Fig. 2), which indicate a significant $(P<0.001)$ departure from panmixia $\left(I_{A}\right.$ and $\left.r_{d}=0\right)$. The frequency of MLG in each population was significantly correlated with AFLP loci obtained, indicating widespread linkage disequilibrium. The average gene diversity, Shannon's index, and evenness were estimated to be $0.13,0.24$, and 1 , respectively. Private alleles were found in all populations; the highest number was observed in Asia, followed by Uganda.

All populations showed low values of genetic differentiation $\left(G_{S T}\right)$, with an overall average among populations of 0.11 (Table 3$)$. Low interpopulation genetic differentiation $(\theta=0.078,95 \%$ confidence interval $=0.057$ to 0.099 ) was equally found when the data were analyzed with TFPGA. Moreover, AMOVA, at two hierarchical levels $\left(\mathrm{F}_{\mathrm{ST}} 0.12\right.$ and $\left.\mathrm{F}_{\mathrm{CT}} 0.11\right)$, indicated that the populations were not geographically structured. Thus, most of the genetic variation was distributed within populations $(88.09 \%)$ 
$(P<0.001,1,023$ nonparametric permutations) rather than among groups (Asia, West Africa, and EA) (10.97\%), and no significant variation existed between populations within groups $(0.93 \%)$ (Table 4). Correspondingly, gene flow between populations was high (>1). Gene flow was highest between Uganda and Rwanda $(\mathrm{Nm}=16.78)$, Tanzania and Uganda $(\mathrm{Nm}=13.10)$, and Tanzania and Rwanda $(\mathrm{Nm}=10.84)$, and was consistent with $I_{A}$ and population evenness. Tanzania, Uganda, and Rwanda also recorded the highest indices of genetic identity and the lowest levels of genetic distance, corroborating the data obtained for gene flow and genetic differentiation. Conversely, gene flow between Asian and African populations was relatively low.

Cluster analysis. PCoA, based on Nei's genetic distance, grouped the isolates into four main clusters (Fig. 3A). The PCoA captured $54.1 \%$ of the total variation in two principal components. The first principal component accounted for $35.7 \%$ of the total variation and illustrated the outgroup position of the Philippine isolates (group 1). Group 2 constituted the largest admixed group followed by group 3. Isolates from the various collection sites formed 15 subpopulations (Fig. 3B). Tanzanian subpopulations were closer to the West African subpopulation, whereas Rwanda and Uganda were found closer to each other. Using STRUCTURE 2.3, Ln probabilities $(\mathrm{X} \mid \mathrm{K})$ for $\mathrm{K}$ values (number of assumed populations) of 1 to 10 were calculated, and $\mathrm{K}=5 \mathrm{had}$ the highest probability (Fig. 4A). Thus, five genetic groups were resolved (Fig. 4B). The results showed a clear separation of the Philippine isolates from the African groups. Among the African populations, West African isolates were the genetically most homogeneous, which was consistent with the 0 private alleles and the high $I_{A}$ values observed (Table 2). Populations from Uganda, Tanzania, and Rwanda had a large proportion of admixed individuals, which corroborates the trend observed in the PCoA clustering. Interestingly, we found that variation in AFLP genotypes was not predictive (not correlated) of variation in pathogenicity.

Pathogenicity assays. Isolates varied in pathogenicity, as reflected by the percent leaf area infected (Table 1). At 10 days postinoculation (dpi), $76 \%$ of isolates had induced severity scores of $\geq 50 \%$. The remaining $24 \%$ consistently produced restricted lesion sizes. The most virulent isolates were TAN211.8 and 507RWA11 from Tanzania and Rwanda, respectively. The least virulent isolate

TABLE 1. Code, designation, country of origin, site of collection, year of collection, cultivars from which the strains were isolated, mating type, and area under the disease progress curve (AUDPC) obtained from pathogenicity tests

\begin{tabular}{|c|c|c|c|c|c|c|c|}
\hline Number & Code & Designation & Country & Site of collection & Cultivar & Mating type & $\mathrm{AUDPC}^{\mathrm{z}}$ \\
\hline 1 & 1026 & 501UGA09 & Uganda & Tilda, Bugiri & Pusa Basmati & MAT1-2 & $495.0 \mathrm{de}$ \\
\hline 2 & 1027 & 502UGA09 & Uganda & Tilda, Bugiri & Pusa Basmati & MAT1-2 & 480.0 def \\
\hline 3 & 1028 & 503UGA09 & Uganda & Tilda, Bugiri & Pusa Basmati & MAT1-2 & $215.0(2) \mathrm{i}-1$ \\
\hline 4 & 1029 & 504UGA09 & Uganda & Tilda, Bugiri & Pusa Basmati & MAT1-2 & $\ldots$ \\
\hline 5 & 1030 & 505UGA09 & Uganda & Tilda, Bugiri & Pusa Basmati & MAT1-2 & $452.5 \mathrm{fgh}$ \\
\hline 6 & 1031 & 508UGA09 & Uganda & Tilda, Bugiri & Pusa Basmati & MAT1-1 & $235.0(2) \mathrm{f}-\mathrm{k}$ \\
\hline 7 & 1032 & 513UGA09 & Uganda & Tilda, Bugiri & Pusa Basmati & MAT1-1 & $470.0 \mathrm{~d}-\mathrm{g}$ \\
\hline 8 & 1033 & 518UGA09 & Uganda & Tilda, Bugiri & Pusa Basmati & MAT1-2 & $225.0(2) \mathrm{h}-\mathrm{k}$ \\
\hline 9 & 1035 & 520UGA09 & Uganda & Tilda, Bugiri & Pusa Basmati & MAT1-2 & $327.5 \mathrm{~s}-\mathrm{w}$ \\
\hline 10 & 1037 & 524UGA09 & Uganda & Tilda, Bugiri & Pusa Basmati & MAT1-2 & $330.0 \mathrm{r}-\mathrm{v}$ \\
\hline 11 & 1106 & 531UGA11 & Uganda & Lira Itek Main Dam & Unknown & MAT1-1 & $510.0 \mathrm{~cd}$ \\
\hline 12 & 1108 & 533UGA11 & Uganda & Lira Itek Main Dam & Unknown & MAT1-1 & $155.0(2) \mathrm{nm}$ \\
\hline 13 & 1112 & 537UGA11 & Uganda & Soroti-Apalitunga & Unknown & MAT1-1 & $267.5(2) a-g$ \\
\hline 14 & 1113 & 538UGA11 & Uganda & Soroti-Apalitunga & Unknown & MAT1-1 & 282.5 yz(2)a-e \\
\hline 15 & 1114 & 539UGA11 & Uganda & Lira-Abolet & Unknown & MAT1-1 & $330.0 \mathrm{r}-\mathrm{V}$ \\
\hline 16 & 1116 & 541UGA11 & Uganda & Lira-Abolet & Unknown & MAT1-1 & $250.0(2) \mathrm{c}-\mathrm{i}$ \\
\hline 17 & 1117 & 542UGA11 & Uganda & Namulonge & NERICA 4 & MAT1-2 & $387.5 \mathrm{k}-\mathrm{p}$ \\
\hline 18 & 1121 & 547UGA11 & Uganda & Namulonge & NERICA 2 & MAT1-1 & $325.0 \mathrm{~s}-\mathrm{x}$ \\
\hline 19 & 1122 & 548UGA11 & Uganda & Namulonge & NERICA 3 & MAT1-2 & $\ldots$ \\
\hline 20 & 1123 & 549UGA11 & Uganda & Namulonge & NERICA 4 & MAT1-2 & $332.5 \mathrm{r}-\mathrm{u}$ \\
\hline 21 & 1126 & 552UGA11 & Uganda & Butaleja, Doho Rice Scheme & K98 & MAT1-1 & $197.5(2) \mathrm{kl}$ \\
\hline 22 & 1129 & 556UGA 11 & Uganda & Namulonge & Pakistan & MAT1-1 & $\ldots$ \\
\hline 23 & 1130 & 557UGA11 & Uganda & Namulonge & Unknown & MAT1-1 & $265.0(2) \mathrm{a}-\mathrm{h}$ \\
\hline 24 & 1132 & 559UGA11 & Uganda & Balita-Wakiso & NERICA 4 & MAT1-1 & $412.5 \mathrm{i}-\mathrm{m}$ \\
\hline 25 & 1142 & 563UGA11 & Uganda & Doho-Butaleja & K98 & MAT1-1 & $255.0(2) \mathrm{b}-\mathrm{i}$ \\
\hline 26 & 1111 & 536UGA11 & Uganda & & & $\underline{-}$ & $370.0 \mathrm{n}-\mathrm{r}$ \\
\hline 27 & 1092 & 495UGA11 & Uganda & & & MAT1-1 & $245.0(2) \mathrm{e}-\mathrm{j}$ \\
\hline 28 & 1298 & $\mathrm{Ugm} 4$ & Uganda & Doho-Butaleja & K98 & MAT1-1 & $295.0 \mathrm{u}-\mathrm{z}(2) \mathrm{ab}$ \\
\hline 29 & 1299 & Lira 1-1 & Uganda & Lira Itek Main Dam & unknown & MAT1-1 & 482.5 def \\
\hline 30 & 1300 & Ugm1 & Uganda & Doho-Butaleja & K98 & MAT1-1 & $350.0 \mathrm{p}-\mathrm{t}$ \\
\hline 31 & 1301 & Ugm2 & Uganda & Doho-Butaleja & K98 & MAT1-1 & $\ldots$ \\
\hline 32 & 1019 & 461RWA09 & Rwanda & Nyazatare experiment station & Nyiragakara & MAT1-1 & $\ldots$ \\
\hline 33 & 1021 & 470RWA09 & Rwanda & Nyazatare experiment station & Nyiragakara & MAT1-1 & $250.0(2) \mathrm{c}-\mathrm{i}$ \\
\hline 34 & 1022 & 474RWA09 & Rwanda & Nyazatare experiment station & Nyiragakara & MAT1-1 & $400.0 \mathrm{j}-\mathrm{m}$ \\
\hline 35 & 1023 & 482RWA09 & Rwanda & Nyazatare experiment station & Nyiragakara & MAT1-1 & $220.0(2) \mathrm{i}-1$ \\
\hline 36 & 1024 & 488RWA09 & Rwanda & Nyazatare experiment station & Nyiragakara & MAT1-1 & $437.5 \mathrm{~g}-\mathrm{j}$ \\
\hline 37 & 1025 & 492RWA09 & Rwanda & Nyazatare experiment station & Nyiragakara & MAT1-1 & $310.0 \mathrm{t}-\mathrm{Z}$ \\
\hline 38 & 1090 & 493RWA11 & Rwanda & Cyabayaga & Kavamahanga & MAT1-1 & $370.0 \mathrm{n}-\mathrm{r}$ \\
\hline 39 & 1094 & 497RWA11 & Rwanda & Cyabayaga & Kavamahanga & MAT1-1 & $357.5 \mathrm{o}-\mathrm{s}$ \\
\hline 40 & 1095 & 498RWA11 & Rwanda & Cyabayaga & Nyiragakara & MAT1-2 & $285.0 \mathrm{x}-\mathrm{z}(2) \mathrm{a}-\mathrm{e}$ \\
\hline 41 & 1099 & 504RWA11 & Rwanda & Cyabayaga & Nyiragakara & MAT1-1 & $182.5(2) 1 \mathrm{~lm}$ \\
\hline 42 & 1133 & 505RWA11 & Rwanda & Cyabayaga & Yunikeng & MAT1-2 & $362.5 \mathrm{n}-\mathrm{s}$ \\
\hline 43 & 1147 & RWA 11.2 & Rwanda & Cyabayaga & Irrigated rice & MAT1-2 & $422.5 \mathrm{i}-1$ \\
\hline 44 & 1149 & 506RWA11 & Rwanda & Cyabayaga & Irrigated rice & MAT1-1 & $360.0 \mathrm{n}-\mathrm{s}$ \\
\hline 45 & 1150 & RWA 11.5 & Rwanda & Cyabayaga & Irrigated rice & MAT1-1 & $227.5(2) \mathrm{g}-\mathrm{k}$ \\
\hline 46 & 1151 & RWA 11.6 & Rwanda & Cyabayaga & Irrigated rice & MAT1-1 & $465.0 \mathrm{e}-\mathrm{h}$ \\
\hline 47 & 1152 & 507RWA11 & Rwanda & Cyabayaga & Irrigated rice & MAT1-1 & $\begin{array}{l}600.0 \text { a } \\
\text { tinued on next page) }\end{array}$ \\
\hline
\end{tabular}

\footnotetext{
${ }^{\mathrm{z}}$ Means followed by the same letter are not significantly different from each other.
} 
was 536UGA11 from Uganda, which showed only 30\% severity. Ten isolates did not produce any visible symptoms on rice seedlings. The same isolates had low sporulation ability when tested on V8 and oatmeal agar plates, and were not included in the second pathogenicity test. Disease progression varied widely. For all pathogenic isolates, a constant increase in the severity scores was observed from 4 to 10 dpi. By comparison, Tanzania and Rwanda had a larger proportion of the more aggressive isolates than Uganda.

MAT distribution. An assay of 88 isolates, based on MATspecific PCR primers, revealed the presence of both MAT1-1 and MAT1-2 in EA (Fig. 4; Table 1). In all, 65 isolates from the various collection sites were MAT1-1 and 17 isolates were MAT1-2. The distribution among isolates was 11, 4, and 2 of MAT1-2 type from Uganda, Rwanda, and Tanzania, respectively. Overall, the frequency of MAT1-1 was higher in EA and predominantly the only MAT in most sites. The representative strains from Asia and West Africa were predominantly MAT1-2.

\section{DISCUSSION}

We analyzed $M$. oryzae populations from EA and representative isolates from West Africa and the Philippines in attempts to infer genetic variability, MAT distribution, and strain pathogenicity. Our data showed low $G_{S T}$ and pairwise population differentiations among EA populations, suggesting a lack of population structure according to Nei's (1978) classification of population differentiation $\left(G_{S T}<0.05\right.$ is low, 0.05 to 0.15 medium, and $>0.15$ high $)$. The absence of a population structure often suggests low genetic diversity, largely due to genetically similar populations (Okori et al. 2004). Such populations are either of common origin or restricted distribution, reproduce exclusively asexually, or experience substantial gene flow coupled with genetic drift (e.g., due to limited host availability). However, in populations where mutation rates are high, it has been suggested that the $G_{S T}$ tends to fall back to zero as more novel alleles are added to a population. This happens because of the negative dependence of $G_{S T}$ on diversity (Jost 2008), and may occur in the case of $M$. oryzae, in which considerable genetic variation, even in the absence of sexual reproduction, has been reported (Couch et al. 2005). To circumvent the bias that may probably result due to mutation rates, we related $G_{S T}$ values to other genetic diversity indices. Our data revealed a $G_{S T}$ value of 0.04 (Table 3) among the EA populations, suggesting that $96 \%$ of genetic variation is derived from within populations. This is consistent with the low Shannon's indices (0.10 to 0.21) (Table 2). The Shannon's index of 0.21 suggests that more than $78 \%$ of the genetic diversity between populations was accounted for by differences between individuals. This result is contrary to the findings of Kumar et al. (1999), where Shannon's diversity indices of 0.89 to 0.92 were found in the Himalayan highly diverse populations of M. oryzae. This might be because EA populations represent recent founder populations where only a few generations have passed since colonization.

We used $I_{A}$ to test the degree of nonrandom association between alleles at different loci (linkage disequilibrium). The $I_{A}$ calculated

TABLE 1. (continued from preceding page)

\begin{tabular}{|c|c|c|c|c|c|c|c|}
\hline Number & Code & Designation & Country & Site of collection & Cultivar & Mating type & $\mathrm{AUDPC}^{\mathrm{z}}$ \\
\hline 48 & 1156 & 508RWA11 & Rwanda & Cyabayaga & Irrigated rice & MAT1-1 & $207.5(2) \mathrm{j}-1$ \\
\hline 49 & 1158 & 510RWA11 & Rwanda & Cyabayaga & Irrigated rice & MAT1-1 & $\ldots$ \\
\hline 50 & 1096 & 500RWA11 & Rwanda & Cyabayaga & Irrigated rice & MAT1-2 & $290.0 \mathrm{v}-\mathrm{z}(2) \mathrm{abc}$ \\
\hline 51 & 1159 & 511RWA11 & Rwanda & Cyabayaga & Irrigated rice & MAT1-1 & $230.0(2) \mathrm{g}-\mathrm{k}$ \\
\hline 52 & 1163 & TAN211.1 & Tanzania & Dakawa & Supa & MAT1-1 & $350.0 \mathrm{p}-\mathrm{t}$ \\
\hline 53 & 1164 & TAN211.2 & Tanzania & Igurusi & SARO & MAT1-1 & $495.0 \mathrm{de}$ \\
\hline 54 & 1165 & TAN211.3 & Tanzania & Kikusya & Unknown & MAT1-1 & $\ldots$ \\
\hline 55 & 1166 & TAN211.4 & Tanzania & Kikusya & Unknown & MAT1-2 & $280.0 \mathrm{yz}(2) \mathrm{a}-\mathrm{e}$ \\
\hline 56 & 1167 & TAN211.5 & Tanzania & Kikusya & Unknown & MAT1-1 & 280.0 yz(2)a-e \\
\hline 57 & 1169 & TAN211.8 & Tanzania & Kikusya & Unknown & MAT1-2 & $577.5 \mathrm{ab}$ \\
\hline 58 & 1170 & TAN211.9 & Tanzania & Kikusya & Unknown & MAT1-1 & $380.0 \mathrm{~m}-\mathrm{q}$ \\
\hline 59 & 1171 & TAN211.10 & Tanzania & Kyela & V35 & MAT1-1 & $392.5 \mathrm{k}-\mathrm{O}$ \\
\hline 60 & 1172 & TAN211.11 & Tanzania & Kyela & V36 & MAT1-1 & $350.0 \mathrm{p}-\mathrm{t}$ \\
\hline 61 & 1173 & TAN211.12 & Tanzania & Kyela & V37 & MAT1-1 & $\ldots$ \\
\hline 62 & 1174 & TAN211.13 & Tanzania & Kyela & V38 & MAT1-1 & $380.0 \mathrm{~m}-\mathrm{q}$ \\
\hline 63 & 1175 & TAN211.14 & Tanzania & Kyela & V39 & MAT1-1 & $380.0 \mathrm{~m}-\mathrm{q}$ \\
\hline 64 & 1176 & TAN211.15 & Tanzania & Kyela & V40 & MAT1-1 & $250.0(2) c-i$ \\
\hline 65 & 1178 & TAN211.17 & Tanzania & Kyela & V40 & MAT1-1 & $537.5 \mathrm{bc}$ \\
\hline 66 & 1180 & RBELOK-10-7-3 & Benin & Lokossa & Unknown & MAT1-2 & $335.0 \mathrm{r}-\mathrm{u}$ \\
\hline 67 & 1181 & RBELOK-10-11-2 & Benin & Lokossa & Unknown & MAT1-1 & $345.0 \mathrm{q}-\mathrm{t}$ \\
\hline 68 & 1182 & RBELOK-10-13-3 & Benin & Lokossa & Unknown & MAT1-2 & $245.0(2) \mathrm{e}-\mathrm{j}$ \\
\hline 69 & 1184 & RNIIBAD-09-5-1 & Nigeria & Ibadan & Unknown & MAT1-2 & $245.0(2) \mathrm{e}-\mathrm{j}$ \\
\hline 70 & 1185 & RNIIBAD-09-82-2 & Nigeria & Edozhigi & Unknown & MAT1-2 & $265.0(2) \mathrm{a}-\mathrm{h}$ \\
\hline 71 & 1187 & RNIIBAD-09-82-3 & Nigeria & Edozhigi & Unknown & MAT1-2 & $382.51-\mathrm{p}$ \\
\hline 72 & 1183 & RBELOK-1022 & Benin & Lokossa & Unknown & MAT1-2 & $425.0 \mathrm{i}-\mathrm{k}$ \\
\hline 73 & 1179 & RBELOK-10-2-4 & Benin & Lokossa & Unknown & MAT1-1 & $447.5 \mathrm{f}-\mathrm{i}$ \\
\hline 74 & 955 & 43 & Philippines & IRRI & Unknown & MAT1-2 & $447.5 \mathrm{f}-\mathrm{i}$ \\
\hline 75 & 957 & AGT211 & Philippines & unknown & Unknown & MAT1-2 & $287.5 \mathrm{w}-\mathrm{z}(2) \mathrm{a}-\mathrm{d}$ \\
\hline 76 & 958 & V86014 & Philippines & IRRI & Unknown & MAT1-2 & $247.5(2) \mathrm{d}-\mathrm{j}$ \\
\hline 77 & 959 & B90289 & Philippines & IRRI & Unknown & MAT1-2 & $312.5 \mathrm{t}-\mathrm{Z}$ \\
\hline 78 & 961 & M36-1-3-10-1 & Philippines & IRRI blast nursery & Unknown & MAT1-2 & $272.5 \mathrm{z}(2) \mathrm{a}-\mathrm{f}$ \\
\hline 79 & 963 & C9228-37 & Philippines & Caliraya, Laguna & Unknown & MAT1-2 & $370.0 \mathrm{n}-\mathrm{r}$ \\
\hline 80 & 977 & V86010 & Philippines & Bo.Bula, Camarines Sur & Unknown & MAT1-2 & $315.0 \mathrm{t}-\mathrm{y}$ \\
\hline 81 & 969 & M39-1-2-21-2 & Philippines & IRRI blast nursery & Unknown & MAT1-2 & $245.0(2) \mathrm{e}-\mathrm{j}$ \\
\hline 82 & 970 & M39-1-3-8-1 & Philippines & IRRI blast nursery & Unknown & MAT1-2 & $275.0 \mathrm{yz}(2) \mathrm{a}-\mathrm{f}$ \\
\hline 83 & 973 & B90002 & Philippines & Caliraya, Laguna & Unknown & MAT1-2 & $295.0 \mathrm{u}-\mathrm{z}(2) \mathrm{ab}$ \\
\hline 84 & 974 & M101-1-1-2-9-1 & Philippines & IRRI blast nursery & Unknown & MAT1-2 & $\ldots$ \\
\hline 85 & 976 & V850256 & Philippines & Cavinti, Laguna & Unknown & MAT1-2 & $310.0 \mathrm{t}-\mathrm{Z}$ \\
\hline 86 & 983 & Ken53-33 & Japan & unknown & Unknown & MAT1-2 & $302.5 \mathrm{u}-\mathrm{z}(2) \mathrm{a}$ \\
\hline 87 & 952 & $\mathrm{Ca} 89$ & Philippines & Cavinti, Laguna & Unknown & MAT1-2 & $250.0(2) \mathrm{c}-\mathrm{i}$ \\
\hline 88 & 960 & V86046 & Philippines & Roxas, Palawan & Unknown & MAT1-2 & $\ldots$ \\
\hline
\end{tabular}


for all populations suggested clonality (Fig. 2), and was consistent with the population evenness and MLG. This indicates widespread linkage disequilibrium and suggests that $M$. oryzae populations from EA are limited to a small number of mostly closely related isolates. A similar pattern was observed with the West African reference collections. In the Asian collection, the number of private alleles was substantially larger, which indicates a greater proportion of diverse alleles compared with EA populations. The relatively short history of rice cultivation and the narrow genetic base of rice germplasm in EA compared with traditional rice-growing areas (e.g., South and Southeast Asia) may be thought of as a contributing factor. Indeed, intensive rice cultivation in EA occurred only recently, when Asian and West African developed varieties were introduced. These introduced cultivars could be causing minor shifts in $M$. oryzae populations already adapted, and may probably take some time for variations to cause a detectable differentiation. In contrast, populations of $M$. oryzae from South and Southeast Asia, where there is a high diversity of rice cultivars, are highly diverse, and clonality is not very obvious (Chen et al. 1995; Kumar et al. 1999; Park et al. 2003).

Exact tests of population differentiation also showed no evidence of differentiation between EA populations (data not shown), which

TABLE 2. Genetic diversity parameters for the East African and representative Asian and West African rice blast strains ${ }^{\mathrm{z}}$

\begin{tabular}{|c|c|c|c|c|c|c|c|c|}
\hline Population & $N$ & Gene diversity & Shannon's index & $\% \mathrm{Pol}$ & $I_{A}$ & $r_{d}$ & MLG & Number of private alleles \\
\hline Tanzania & 14.0 & 0.12 & 0.19 & 49.0 & 4.19 & 0.05 & 14.0 & 2.0 \\
\hline Uganda & 31.0 & 0.12 & 0.21 & 68.7 & 3.76 & 0.03 & 31.0 & 8.0 \\
\hline Rwanda & 20.0 & 0.13 & 0.21 & 60.1 & 7.21 & 0.06 & 20.0 & 5.0 \\
\hline West Africa & 8.0 & 0.09 & 0.15 & 31.3 & 9.94 & 0.17 & 8.0 & 0.0 \\
\hline Asia & 15.0 & 0.13 & 0.20 & 48.5 & 3.93 & 0.04 & 15.0 & 28.0 \\
\hline Mean & $\ldots$ & 0.13 & 0.24 & 51.52 & 5.81 & 0.07 & $\ldots$ & $\ldots$ \\
\hline
\end{tabular}

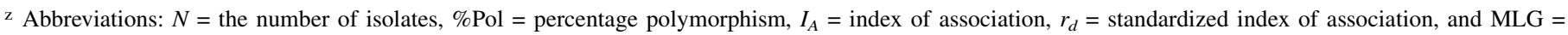
multilocus genotypes.
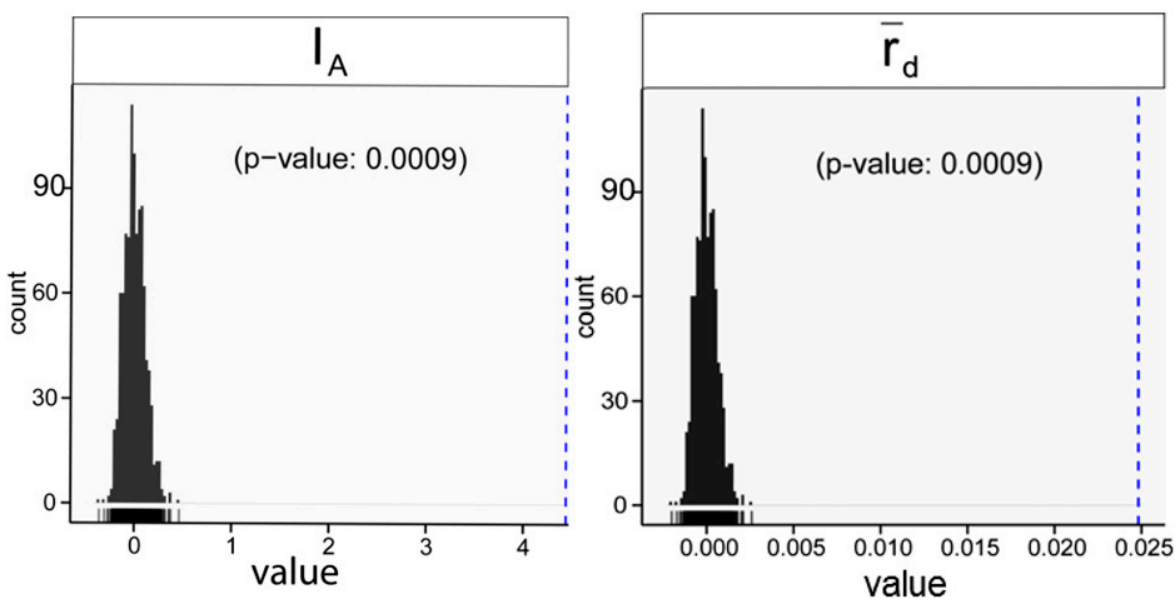

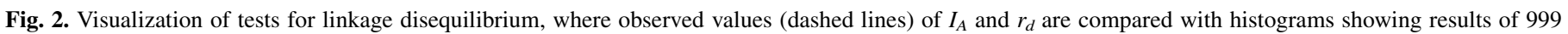
permutations using the poppr R package. All populations were clonal (observed value is significantly different from the expected panmixia).

TABLE 3. Genetic differentiation $\left(G_{S T}\right)$, gene flow $(\mathrm{Nm})$, genetic distance (GD), and genetic identity (I) among and between East African Magnaporthe oryzae populations and selected Asian and West African groups ${ }^{\mathrm{z}}$

\begin{tabular}{|c|c|c|c|c|c|c|c|c|c|c|}
\hline \multirow[b]{2}{*}{ Population } & \multicolumn{5}{|c|}{$G_{S T}$} & \multicolumn{5}{|c|}{ I } \\
\hline & A & $\mathrm{R}$ & $\mathrm{U}$ & $\mathrm{T}$ & W & A & $\mathrm{R}$ & $\mathrm{U}$ & $\mathrm{T}$ & W \\
\hline Asia $(n=15)$ & $\ldots$ & 0.12 & 0.09 & 0.10 & 0.14 & & 0.962 & 0.971 & 0.969 & 0.960 \\
\hline Rwanda $(n=20)$ & 3.72 & $\ldots$ & 0.03 & 0.04 & 0.08 & 0.039 & $\ldots$ & 0.992 & 0.987 & 0.979 \\
\hline Tanzania $(n=14)$ & 4.31 & 10.84 & 13.10 & $\ldots$ & 0.07 & 0.032 & 0.013 & 0.010 & $\ldots$ & 0.982 \\
\hline West Africa $(n=8)$ & 3.04 & 5.97 & $\begin{array}{l}5.17 \\
\mathrm{Nm}\end{array}$ & 7.06 & $\ldots$ & 0.041 & 0.021 & $\begin{array}{c}0.024 \\
\text { GD }\end{array}$ & 0.017 & $\ldots$ \\
\hline
\end{tabular}

z Abbreviations: A = Asia, $\mathrm{R}=\mathrm{Rwanda}, \mathrm{U}=\mathrm{Uganda}, \mathrm{T}=$ Tanzania, $\mathrm{B}=$ Benin, and $\mathrm{N}=$ Nigeria. $G_{S T}$ and $\mathrm{I}$ are in the upper diagonals in the left and right panels of the table, respectively. Gene flow estimated as $G_{S T}=0.5\left(1-G_{S T}\right) / G_{S T}(\mathrm{Nm})$; GD is in the lower diagonal of left and right panels, respectively.

TABLE 4. Results of analysis of molecular variance for populations of Magnaporthe oryzae sampled from East Africa, West Africa, and Asia

\begin{tabular}{|c|c|c|c|c|}
\hline Source of variation & $\mathrm{df}$ & Sum of squares & Variance components & Variation $(\%)$ \\
\hline Among groups & 2 & 85.04 & $1.57 \mathrm{Va}$ & 10.97 \\
\hline Among populations within groups & 4 & 57.41 & $0.13 \mathrm{Vb}$ & 0.93 \\
\hline Within populations & 81 & 1021.25 & $12.61 \mathrm{Vc}$ & 88.09 \\
\hline Total & 87 & 1163.71 & 14.31 & $\ldots$ \\
\hline
\end{tabular}


is consistent with the $G_{S T}$ values. In addition, pairwise comparisons using genetic identity and genetic distances showed low genetic diversity, further indicating that $M$. oryzae populations at the studied sites were relatively homogenous and stable over the study period. Similar population structures have been observed in Europe

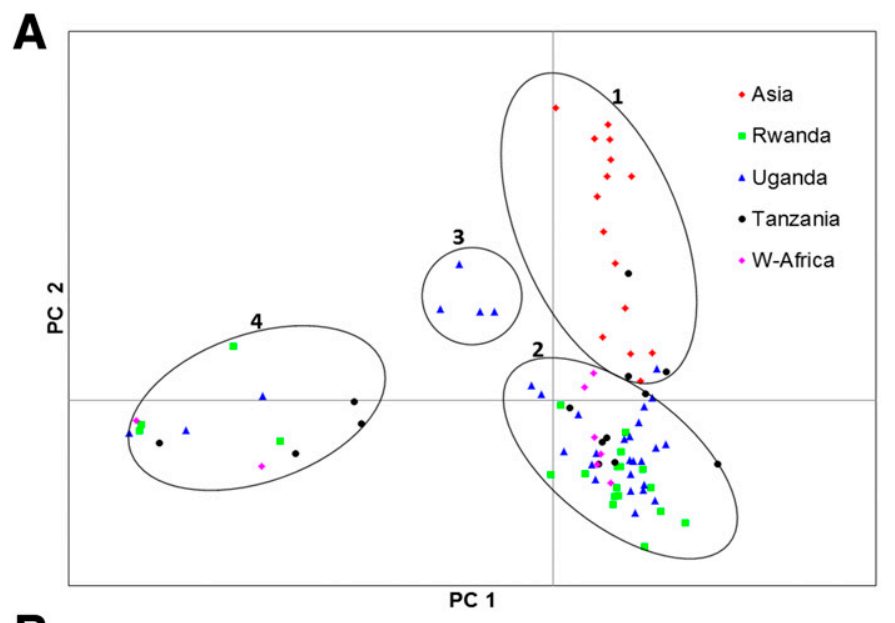

B

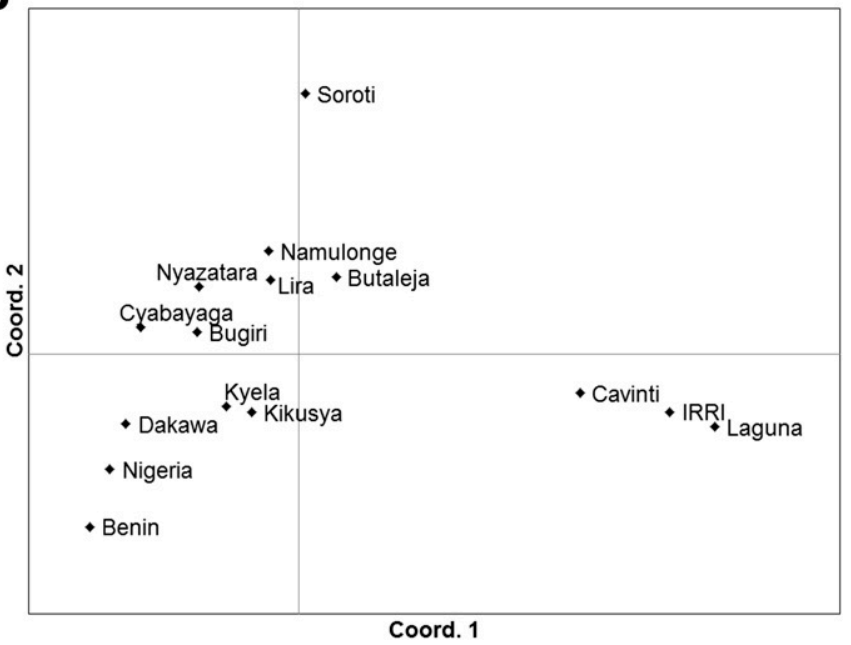

Fig. 3. A, Principal coordinate analysis of Magnaporthe oryzae isolates from East Africa and representative strains from Philippines and West Africa. The first and second principal coordinates account for 35.73 and $18.37 \%$ of the variation, respectively. Numbers $1,2,3$, and 4 indicate cluster groupings. B, Principal coordinate analysis of $M$. oryzae subgroups from East Africa and representative strains from Philippines and West Africa. Isolates from the various collection sites are pooled into 15 subgroups. Subgroups Namulonge, Doho (Butaleja), Lira, and Tilda (Bugiri) represent Uganda; Nyazatara and Cyabayaga represent Rwanda; Dakawa, Kyela, and Kikusya represent Tanzania; Cavinti, IRRI, and Laguna represent Philippines; and Nigeria and Benin represent West Africa.
(Piotti et al. 2005; Roumen et al. 1997), Iran (Javan-Nikkah et al. 2004), the United States (Correll et al. 2009; Levy et al. 1991; Xia et al. 1993), Argentina (Consolo et al. 2008), Colombia (Levy et al. 1993; Zeigler 1998), Cuba (Fuentes et al. 2003), and West Africa (Takan et al. 2012), in which only a few lineages were detected. Therefore, it appears that either selection pressures have played a weak role in altering allele frequencies or a scenario similar to the aforementioned areas could be shaping the EA populations. Another explanation could be that any selection pressures that exist to influence allele frequencies are not confined to a particular geographic area in EA. On the other hand, $M$. oryzae has been present in EA for over 90 years, and this provides less direct but intriguing evidence that the effect of a colonization bottleneck and subsequent clonal growth could have shaped the EA populations.

The use of hierarchical AMOVA (Table 4) further supports these findings, and corresponds with the strong indication of gene flow detected in this study. Gene flow involves the introduction or reintroduction of genes to a population, and our results indicate that gene flow in EA populations is comparable with that reported for geographically distant wheat blast populations in Brazil (Maciel et al. 2014) and other ascomycete fungi (e.g., Mycosphaerella graminicola) (Zhan et al. 2003). This evidence for extensive gene flow in Magnaporthe oryzae indicates the ongoing connection between the EA populations, though alternative explanations are also possible. There may be two possible scenarios: either the high gene flow results from the movement of planting materials between these countries or from movement of M. oryzae strains to EA via different other routes or at different times but from a common source, homogenizing the effect of gene flow. If germplasm movement is the cause of high gene flow, we speculate that Uganda could represent a focal point from which the pathogen was established first, considering the relatively high gene diversity and the striking admixture (Fig. 4B). However, due to the low sample size of isolates from the other countries studied, such analyses will have to be carefully considered, and continued genetic analysis of additional samples, as they become available, will help to verify this argument. Thus, the genetic clustering observed in our data may reflect either germplasm movement or historical patterns of gene flow that occurred decades ago, which could be both long-lived and able to propagate through asexual reproduction. In both cases, regional efforts to abate disease outbreaks through joint resistance breeding are plausible.

The PCoA, based on Nei's genetic distance, captured only $54.1 \%$ of the total variation in two principal components, suggesting limited robustness in the strain grouping. Only the spatial analysis of principal components revealed a slight geographical pattern among the subpopulations. The clustering pattern generated from STRUCTURE 2.3 also did not follow the geographical origin, except for isolates from Philippines, thus supporting the mixed pattern depicted in PCoA. The results obtained from STRUCTURE also show that isolates from Uganda are distributed in all clusters,

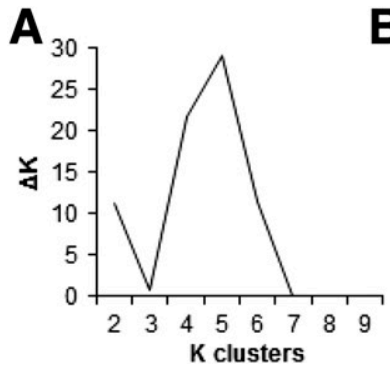

B

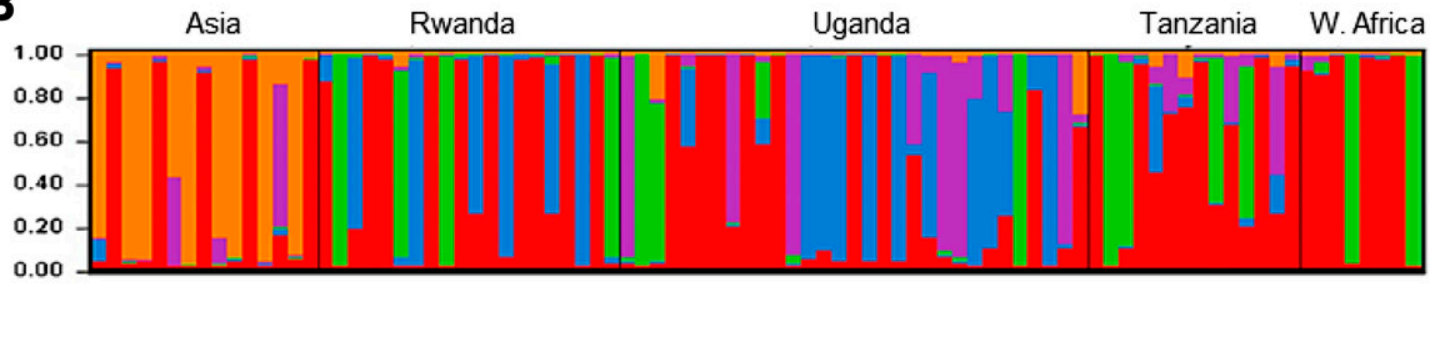

Fig. 4. Graphical representation of the results obtained from STRUCTURE. A, The most probable value of K, determined by $\Delta \mathrm{K}$ for 88 strains $(x$-axis) sorted by membership coefficients ( $y$-axis) within clusters $(K=5)$. B, STRUCTURE plot of the 88 isolates with $\mathrm{K}=5$ clusters. The plot is sorted according to the origin of isolates. Different colors represent genetic groups. Each column represents an individual partitioned into segments representing the estimated coefficients of membership proportions in the five ancestral genetic clusters (genetic groups) inferred with STRUCTURE. The height of the column segments shows the probability of assignment of individual isolates to the genetic groups based on 100,000 runs. 
and is consistent with the historical reports of the first detection of the pathogen in Africa (Small 1922), although it would have been present in earlier times than 1921.

Interestingly, both MAT1-1 and MAT1-2 were detected, although with location-specific differences and skewed ratio toward MAT1-1 in all EA populations. Such a skewed pattern of MAT distribution has been also observed in West Africa (Takan et al. 2012). It is common for one MAT to be dominant in field populations, with most of the isolates being male fertile or completely sterile (Tredway et al. 2005). Moreover, recombinants are rarely reported in such scenarios. Whether the EA strains are able to reproduce sexually remains to be determined. However, the skewed distribution of the two MAT and the significant and positive $I_{A}$ values suggest clonal or mixed reproduction within populations but not sexual reproduction. Thus, we hypothesize that the introduction of isolates with two MAT could have occurred in EA. However, the exact localization of the source population and the time of introduction of both MAT remain to be determined. The difference in MAT distribution between Philippine and most EA isolates suggests that EA isolates could have originated from a source other than the Philippines, which may require a substantially large sample size to verify, including isolates from regions other than the Philippines. Several lines of research that pertain to this issue are in progress that will further our understanding of M. oryzae origin and distribution in EA.

In our pathogenicity study, isolates showed differences in severity and disease progress. By comparison of virulence on Co39, Tanzania and Rwanda had a higher percentage of virulent isolates than Uganda. However, the high pathogenic variability was not consistent with the population structure, suggesting that $M$. oryzae populations in EA are dominated by genetically less diverse strains but diverse pathotypes, which is similar to the populations previously reported in Japan (Don et al. 1999) and South Korea (Park et al. 2003). This scenario suggests that pathogenicity is labile to be predicted by linkage with neutral markers in these population samples.

Overall, our results showed low genetic differentiation, skewed distribution of the two MAT, and a possible role of gene flow in $M$. oryzae populations from EA. Either M. oryzae could be distributed as a single genetic population in EA or that gene flow is exerting a significant influence, effectively swamping the action of selection. In this way, the alleles present in Tanzania, Uganda, and Rwanda are primarily subsets, with the exception of a few new alleles which could have been created by mutations. These rare alleles could be the reason for the variable pathogenicity observed in EA populations. Although AFLP screens a large number of polymorphic loci, diversity estimates reported in the present study will have to be carefully considered and may need to be confirmed with other marker systems, which could broaden the molecular understanding of the EA pathogen population. Future research should also focus on identifying the source population and study further the evolutionary potential of EA isolates with additional sampling and long-term monitoring. The use of a standard set of differential rice lines with single resistance genes for race differentiation would provide further evidence for pathogenic diversity. The effect of high temperature associated with climate change on recent rice blast outbreaks observed in EA will have to be carefully considered because little is known about the biology of this pathogen in EA.

\section{ACKNOWLEDGMENTS}

This work was funded by the Germany Federal Ministry of Economic Cooperation and Development, Deutsche Gesellschaft für Internationale Zusammenarbeit GmbH. We thank P. Karlovsky for his helpful suggestions for this work; R. Pilot, E. Vorbeck, and D. Tacke for their technical support; C. Kukunda for help in drawing the map; and N. Grünwald for help in data analysis.

\section{LITERATURE CITED}

Borromeo, E. S., Nelson, R. J., Bonman, J. M., and Leung, H. 1993. Genetic differentiation among isolates of Pyricularia infecting rice and weed hosts. Phytopathology 83:393-399.

Brandfass, C., and Karlovsky, P. 2008. Upscaled CTAB-based DNA extraction and real-time PCR assays for Fusarium culmorum and F. graminearum DNA in plant material with reduced sampling error. Int. J. Mol. Sci. 9: 2306-2321.

Brondani, C., Brondani, R. P. V., Garrido, L., Da, R., and Ferreira, M. E. 2000. Development of microsatellite markers for genetic analysis of Magnaporthe grisea. Genet. Mol. Biol. 23:753-762.

Campbell, C. L., and Madden, L. V. 1990. Introduction to Plant Disease Epidemiology. John Wiley \& Sons, New York.

Chen, D., Zeigler, R. S., Leung, H., and Nelson, R. J. 1995. Population structure of Pyricularia grisea at two screening sites in the Philippines. Phytopathology 85:1011-1020.

Consolo, V. F., Cordo, C. A., and Salerno, G. L. 2008. DNA fingerprint and pathotype diversity of Pyricularia oryzae populations from Argentina. Austral. Plant Pathol. 37:357-364.

Consolo, V. F., Cordo, C. A., and Salerno, G. L. 2005. Mating-type distribution and fertility status in Magnaporthe grisea populations from Argentina. Mycopathologia 160:285-290.

Correll, J. C., Boza, E. J., Seyran, E., Cartwright, R. D., Jia, Y., and Lee, F. N. 2009. Examination of the rice blast pathogen population diversity in Arkansas, USA-Stable or unstable? Pages 217-228 in: Advances in Genetics, Genomics and Control of Rice Blast Disease. G.-L. Wang and B. Valent, eds. Springer, New York.

Couch, B. C., Fudal, I., Lebrun, M. H., Tharreau, D., Valent, B., van Kim, P., Nottéghem, J. L., and Kohn, L. 2005. Origins of host-specific populations of the blast pathogen Magnaporthe oryzae in crop domestication with subsequent expansion of pandemic clones on rice and weeds of rice. Genetics 170:613-630.

Don, L. D., Urashima, A. S., Tosa, Y., Nakayashiki, H., and Mayama, S. 1999. Population structure of the rice blast fungus in Japan examined by DNA fingerprinting. Ann. Phytopathological Soc. Jpn. 65: 15-24.

Evanno, G., Regnaut, S., and Goudet, J. 2005. Detecting the number of clusters of individuals using the software structure: A simulation study. Mol. Ecol. $14: 2611-2620$

Excoffier, L., Laval, G., and Schneider, S. 2005. Arlequin 3.01: An integrated software package for population genetics data analysis. Evol. Bioinf. Online 1:47-50.

FAOSTAT. 2011. Rough rice area (000 ha), by country and geographical region, 1961-2011. Food and Agricultural Organization of the United Nations-Production Statistics. http://faostat.fao.org/site/567/desktopdefault. aspx\#ancor

Fuentes, J. L., Correa-Victoria, F. J., Escobar, F., Mora, L., Duque, M. C., Deus, J. E., and Cornide, M. T. 2003. Genetic diversity analysis of the rice blast pathogen population at two locations in Cuba. Biotecnol. Apl. 20: 14-19.

Gerber, S., Mariette, S., Streiff, R., Bodénès, C., and Kremer, A. 2000. Comparison of microsatellites and amplified fragment length polymorphism markers for parentage analysis. Mol. Ecol. 9:1037-1048.

Grünwald, N. J., Goodwin, S. B., Milgroom, M. G., and Fry, W. E. 2003. Analysis of genotypic diversity data for populations of microorganisms. Phytopathology 93:738-746.

Javan-Nikkah, M., McDonald, B. A., Banke, S., and Hedjaroude, G.-A. 2004. Genetic structure of Iranian Pyricularia grisea populations based on repPCR fingerprinting. Eur. J. Plant Pathol. 110:909-919.

Jost, L. 2008. GST and its relatives do not measure differentiation. Mol. Ecol. 17:4015-4026

Kachroo, P., Leong, S. A., and Chattoo, B. B. 1994. Pot2, an inverted repeat transposon from the rice blast fungus Magnaporthe grisea. Mol. Gen. Genet. 245:339-348.

Kihoro, J., Njoroge, J. B., Murage, H., Ateka, E., and Makihara, D. 2013. Investigating the impact of rice blast disease on the livelihood of the local farmers in greater Mwea region of Kenya. SpringerPlus 2:308.

Kumar, J., Nelson, R. J., and Zeigler, R. S. 1999. Population structure and dynamics of Magnaporthe grisea in the Indian Himalayas. Genetics 152:971-984.

Levy, M., Correa-Victoria, F. J., Zeigler, R. S., Hu, S., and Hamer, J. E. 1993. Genetic diversity of the rice blast fungus in a disease nursery in Colombia. Phytopathology 83:1427-1433.

Levy, M., Romao, J., Marchetti, M. A., and Hamer, J. E. 1991. DNA fingerprinting with dispersed repeated sequence resolves pathotype diversity in the rice blast fungus. Plant Cell 3:95-102.

Liu, J., Wang, X., Mitchell, T., Hu, Y., Liu, X., Dai, L., and Wang, G. L. 2010. Recent progress and understanding of the molecular mechanisms of the rice-Magnaporthe oryzae interaction. Mol. Plant Pathol. 11:419-427. 
Liu, Z. J., and Cordes, J. F. 2004. DNA marker technologies and their applications in aquaculture genetics. Aquaculture 238:1-37.

Maciel, J. L., Ceresini, P. C., Castroagudin, V. L., Zala, M., Kema, G. H., and McDonald, B. A. 2014. Population structure and pathotype diversity of the wheat blast pathogen Magnaporthe oryzae 25 years after its emergence in Brazil. Phytopathology 104:95-107.

Miller, M. P. 1997. Tools for Population Genetic Analyses (TFPGA) v. 1.3: A Windows Program for the Analysis of Allozyme and Molecular Population Genetic Data. Department of Biological Sciences, Northern Arizona University. http://www.ccg.unam.mx/ vinuesa/tlem09/docs/TFPGADOC.PDF

Mwalyego, F. S., Kayeke, J. M., and Mghogho, R. M. 2011. ASARECA project: Livelihood improvement through integrated management practices for rainfed lowland rice. A guide for farmers. http://www.erails. net/images/tanzania/ari-uyle/ari-uyole/file/Rice\%20diseases\%202011.pdf

Nei, M. 1978. Estimation of average heterozygosity and genetic distance from a small number of individuals. Genetics 89:583-590.

Okori, P., Rubaihayo, P. R., Adipala, E., Fahleson, J., and Dixelius, C. 2004. Population studies of fungal pathogens: Perspectives for control with specific reference to grey leaf spot. Afr. Crop Sci. J. 12:327-342.

Park, S.-Y., Milgroom, M. G., Han, S. S., Kang, S., and Lee, Y.-H. 2003. Diversity of pathotypes and DNA fingerprint haplotypes in populations of Magnaporthe grisea in Korea over two decades. Phytopathology 93:1378-1385.

Peakall, R., and Smouse, P. E. 2006. GENEALEX 6: Genetic analysis in excel. Population genetic software for teaching and research. Mol. Ecol. Notes 6: 288-295.

Piotti, E., Rigano, M. M., Rodino, D., Rodolfi, M., Castiglione, S., Picco, A. M., and Sala, F. 2005. Genetic structure of Pyricularia grisea (Cooke) Sacc. isolates from Italian paddy fields. J. Phytopathol. 153:80-86.

Pritchard, J. K., Stephens, M., and Donnelly, P. 2000. Inference of population structure using multilocus genotype data. Genetics 155:945-959.

Roumen, E., Levy, M., and Notteghem, J. L. 1997. Characterization of the European pathogen population of Magnaporthe grisea by DNA fingerprinting and pathotype analysis. Eur. J. Plant Pathol. 103:363-371.

Saleh, D., Milazzo, J., Adreit, H., Fournier, E., and Tharreau, D. 2014. SouthEast Asia is the center of origin, diversity and dispersion of the rice blast fungus, Magnaporthe oryzae. New Phytol. 201:1440-1456.

Sere, Y., Onasanya, A., Afolabi, A., Mignouna, H. D., and Akator, K. 2007. Genetic diversity of the blast fungus, Magnaporthe grisea (Hebert) Barr. in Burkina Faso. Afr. J. Biotechnol. 6:2568-2577.

Silva G. B., Prabhu, A. S., Filippi, M. C. C., Trindade M. G., Araújo, L. G., and Zambolim, L. 2009. Genetic and phenotypic diversity of Magnaporthe oryzae from leaves and panicles of rice in commercial fields in the State of Goiás, Brazil. Trop. Plant Pathol. 34:71-76.

Small, W. 1922. Annual report of the government mycologist for 1921. An investigation into fungi found on rice in Uganda. Uganda Prot. Dep. Agric. Annu. Rep. Pages 49-57. Rev. Appl. Mycol. 2:156-157.

Stoddart, J. A., and Taylor, J. F. 1988. Genotypic diversity: Estimation and prediction in samples. Genetics 118:705-711.

Takan, J. P., Chipili, J., Muthumeenakshi, S., Talbot, N. J., Manyasa, E. O., Bandyopadhyay, R., Sere, Y., Nutsugah, S. K., Talhinhas, P., Hossain, M., Brown, A. E., and Sreenivasaprasad, S. 2012. Magnaporthe oryzae populations adapted to finger millet and rice exhibit distinctive patterns of genetic diversity, sexuality and host interaction. Mol. Biotechnol. 50: 145-158.

Thuan, T. N. T., Bigirimana, J., Roumen, E., Van Der Straeten, D., and Höfte, M. 2006. Molecular and pathotype analysis of the rice blast fungus in North Vietnam. Eur. J. Plant Pathol. 114:381-396.

Tredway, L. P., Stevenson, K. L., and Burpee, L. L. 2005. Genetic structure of Magnaporthe grisea population associated with St. Augustine grass and tall fescue in Georgia. Phytopathology 95:463-471.

Vos, P., Hogers, R., Bleeker, M., Reijans, M., Vanderlee, T., Hornes, M., Frijters, A., Pot, J., Peleman, J., Kuiper, M., and Zabeau, M. 1995. AFLP: New technique for DNA-fingerprinting. Nucleic Acids Res. 23:4407-4414.

Weiberg, A., and Karlovsky, P. 2009. Components of variance in transcriptomics based on electrophoretic separation of cDNA fragments (cDNA-AFLP). Electrophoresis 30:2549-2557.

Xia, J. Q., Correll, J., Lee, F. N., and Ross, W. J. 2000. Regional population diversity of Pyricularia grisea in Arkansas and the influence of host selection. Plant Dis. 84:877-884.

Xia, J. Q., Correll, J. C., Lee, F. N., Marchetti, M. A., and Rhoads, D. D. 1993. DNA fingerprinting to examine microgeographic variation in the Magnaporthe grisea population in two rice fields in Arkansas. Phytopathology 83: 1029-1035.

Yeh, F. C., and Boyle, T. 1999. POPGENE version 1.3.2: Microsoft windowbased freeware for population genetic analysis. Online publication. https://www. ualberta.ca/ fyeh/popgene.html

Zeigler, R. 1998. Recombination in Magnaporthe grisea. Annu. Rev. Phytopathol. 36:249-275.

Zhan, J., Pettway, R. E., and McDonald, B. A. 2003. The global genetic structure of the wheat pathogen Mycosphaerella graminicola is characterized by high nuclear diversity, low mitochondrial diversity, regular recombination and gene flow. Fungal Genet. Biol. 38:286-297. 